\title{
Polybrominated diphenyl ethers (PBDEs) and alternative brominated flame retardants (aBFRs) in sediments from four bays of the Yellow Sea, North China ${ }^{\text {花 }}$
}

\author{
Xiaomei Zhen a, d, Jianhui Tang ${ }^{\text {a, * }}$, Zhiyong Xie ${ }^{\text {c }}$, Runmei Wang a , Guopei Huang a, d, \\ Qian Zheng ${ }^{\text {b, d, }}$, Kai Zhang ${ }^{\text {e, Yongge Sun }}{ }^{\text {e, Chongguo Tian }}{ }^{\text {a, d }}$, Xiaohui Pan ${ }^{\text {a }}$, Jun Li ${ }^{\text {b', }}$ \\ Gan Zhang ${ }^{b}$ \\ ${ }^{a}$ Key Laboratory of Coastal Environmental Processes and Ecological Remediation, Yantai Institute of Coastal Zone Research, CAS, Yantai, 264003, China \\ b State Key Laboratory of Organic Geochemistry, Guangzhou Institute of Geochemistry, CAS, Guangzhou, 510640, China \\ ${ }^{\mathrm{c}}$ Helmholtz-Zentrum Geesthacht, Centre for Materials and Coastal Research, Max-Planck-Strasse 1, Geesthacht, 21502, Germany \\ d University of Chinese Academy of Sciences, Beijing, 100049, China \\ e School of Earth Sciences, Zhejiang University, Hangzhou, Zhejiang, 310027, China
}

\section{A R T I C L E I N F O}

\section{Article history:}

Received 12 October 2015

Received in revised form

20 February 2016

Accepted 21 February 2016

Available online $\mathrm{xxx}$

\section{Keywords:}

PBDEs

DBDPE

Jiaozhou Bay

Dalian Bay

Yellow Sea

\begin{abstract}
A B S T R A C T
The distribution characteristics and potential sources of polybrominated diphenyl ethers (PBDEs) and alternative brominated flame retardants (aBFRs) were investigated in 54 surface sediment samples from four bays (Taozi Bay, Sishili Bay, Dalian Bay, and Jiaozhou Bay) of North China's Yellow Sea. Of the 54 samples studied, 51 were collected from within the four bays and 3 were from rivers emptying into Jiaozhou Bay. Decabromodiphenylethane (DBDPE) was the predominant flame retardant found, and concentration ranged from 0.16 to $39.7 \mathrm{ng} \mathrm{g}^{-1} \mathrm{dw}$ and $1.13-49.9 \mathrm{ng} \mathrm{g}^{-1} \mathrm{dw}$ in coastal and riverine sediments, respectively; these levels were followed by those of BDE 209, and its concentrations ranged from n.d. to $10.2 \mathrm{ng} \mathrm{g}^{-1} \mathrm{dw}$ and $0.05-7.82 \mathrm{ng} \mathrm{g}^{-1} \mathrm{dw}$ in coastal and riverine sediments, respectively. The levels of DBDPE exceeded those of decabromodiphenyl ether (BDE 209) in most of the samples in the study region, whereas the ratio of DBDPE/BDE 209 varied among the four bays. This is indicative of different usage patterns of brominated flame retardants (BFRs) and also different hydrodynamic conditions among these bay areas. The spatial distribution and composition profile analysis indicated that BFRs in Jiaozhou Bay and Dalian Bay were mainly from local sources, whereas transport from Laizhou Bay by coastal currents was the major source of BFRs in Taozi Bay and Sishili Bay. Both the $\sum$ PBDEs and $\sum$ aBFRs (sum of pentabromotoluene (PBT), 2,3-diphenylpropyl-2,4,6-tribromophenyl ether (DPTE), pentabromoethylbenzene (PBEB), and hexabromobenzene (HBB)) were at low concentrations in all the sediments. This is probably attributable to a combination of factors such as low regional usage of these products, atmospheric deposition patterns, coastal currents transportation patterns, and degradation processes for higher BDE congeners. This paper is the first study that has investigated the levels of DBDPE in the coastal sediments of China's Yellow Sea.
\end{abstract}

() 2016 Elsevier Ltd. All rights reserved.

\section{Introduction}

There were at least 75 brominated flame retardants (BFRs) that are used extensively in electronic appliances, plastics, textiles, and furniture as addictives to prevent fire (Li et al., 2011). In 2011, 390

\footnotetext{
This paper has been recommended for acceptance by Maria Cristina Fossi.

* Corresponding author.

E-mail address: jhtang@yic.ac.cn (J. Tang).
}

thousand tons of BFRs were sold, which represents $19.7 \%$ of the flame retardant markets globally (Wikipedia, 2015). Most studies on BFRs have focused on the following three groups of products: polybrominateddiphenyl ethers (PBDEs) and biphenyls (PBBs), hexabromocyclododecanes (HBCDs), and tetrabromobisphenol $\mathrm{A}$ (TBBP-A) (Covaci et al., 2011).

Polybrominateddiphenyl ethers (including BDE 209) are the most widely used BFRs. Because of concern over their toxicological effects, bans and restrictions on the production and use of three 
commercial PBDE mixtures (penta-BDE, octa-BDE and deca-BDE) have recently been implemented in some regions, such as Europe and the USA (BSEF, 2015). In addition, penta-BDE and octa-BDE formulations have been listed as persistent organic pollutants (POPs) under Annex A of the Stockholm Convention (UNEP, 2009). However, deca-BDE is still used in many countries including China. Meanwhile, some alternative brominated flame retardants (aBFRs) have been produced extensively by manufacturers. For instance, the annual production volume of decabromodiphenylethane (DBDPE), which is a replacement for deca-BDE, have been estimated at 12,000 tons in China (Chen et al., 2013). Recently, some studies have also reported that the levels of DBDPE were comparable to those of BDE 209 in many types of environmental media from different countries (Lee et al., 2014c; Robson et al., 2013; Zhu et al., 2013). Mixtures of bis-(2-ethylhexyl)-tetrabromophthalate (TBPH or BEHTBP) and 2-ethylhexyl-2,3,4,5-tetrabromobenzonate (TBB or EHTBB), and 1,2-bis(2,4,6-tribromophenoxy)ethane (BTBPE or TBE) have been reported as viable replacements for penta-BDE and octa-BDE, respectively (Covaci et al., 2011). Meanwhile, other aBFRs, such as pentabromotoluene (PBT), pentabromoethylbenzene (PBEB), hexabromobenzene (HBB), and 2,3diphenylpropyl-2,4,5-tribromophenyl ether (DPTE) have been detected in air and seawater samples from the European Arctic (Moller et al., 2011), because of their similar long-range atmospheric transport (LRAT) potentials to these of PBDEs.

Previous studies have investigated the spatial distribution of BFRs in background forest soils of China and DBDPE was found to be the most abundant contaminant (Zheng et al., 2015). High concentrations of DBDPE (3100 $\left.\mathrm{ng} \mathrm{g}^{-1} \mathrm{dw}\right)$ and BDE 209 $\left(48,000 \mathrm{ng} \mathrm{g}^{-1} \mathrm{dw}\right)$ were found in sludge samples from industrial wastewater treatment plants (WWTPs) in Korea (Lee et al., 2014c), and DBDPE (with a mean concentration of $52.2 \mathrm{ng} \mathrm{g}^{-1} \mathrm{dw}$ ) was also detected as the most dominant contaminant in sewage sludge samples from 62 WWTPs in China among the 20 halogenated flame retardants and dehalogenated products detected (Zeng et al., 2014); this supports the hypothesis that WWTPs are an important source of these compounds. Wang et al. (2011) investigated flame retardants in the Dalian coastal area and concluded that the effluent of sewage outlets was the major source of these compounds. According to the 'China Marine Environment Quality Bulletin 2014', pollutants from $48 \%$ of the land-based outlets in China are not in full compliance with regulatory standards (SOA, 2014a), and WWTPs remain a significant source of pollution to the sea. During the flood season, the $\sum$ PBDEs (including BDE 209) input to Lake Chaohu from rivers was estimated at $344 \mathrm{~kg} \mathrm{yr}^{-1}$, thus suggesting that river runoff was also an important pathway for the transport of anthropogenic pollutants (Wang et al., 2013).

The concentration of DBDPE ranged from 1.7 to 270 ng sample ${ }^{-1}$ in the atmosphere of North China, and the main source of the DBDPE was the BFRs manufacturing base (Zhao et al., 2013a). The majority of BFR manufacturing facilities are concentrated around the Laizhou Bay area in the Shandong Province, and these compounds maybe released to the environment unintentionally (Pan et al., 2007). Besides the terrestrial sources mentioned above, black carbon (BC) (Fang et al., 2015), atmospheric deposition, and regional hydrodynamic conditions can affect the distribution of BFRs in coastal sediments.

Sediment is a main sink and potential secondary source of POPs and contaminated sediments can produce both direct and indirect effects on the benthos and higher level trophic level organisms via food chain transfers. The coast serves as a transitional and buffering zone between the land and ocean, and high levels of POPs are often detected in such region. The bioaccumulation and transfer behavior of PBDEs has been investigated in marine food webs of Liaodong Bay (Ma et al., 2013) and the Korean coast (Moon et al., 2007b).
aBFRs have similar physical-chemical properties to PBDEs, and they have been observed in fish, sharks, whales, seals, and bird eggs (Covaci et al., 2011). In China, there have been many reports about the concentrations, distributions, and composition patterns of PBDEs in sediments (Lee et al., 2014c; Li et al., 2010; Pan et al., 2010, 2011), but few studies (Chen et al., 2013; Wang et al., 2011, 2015a) have focused on aBFRs, especially in the Yellow Sea. In North China, PBDEs and aBFRs have been reported in the atmosphere (Lin et al., 2013; Zhao et al., 2013a), but very limited data are available about their status in coastal and marine environments in this region.

The Yellow Sea is a marginal sea in the West Pacific Ocean that is situated between China and the Korean Peninsula, and the majority of pollutants here originated from land-based inputs. In 2012, the load from industrial effluents to the Yellow Sea from seven main coastal cities (including Dalian, Qingdao, Yantai, Weifang, Weihai, Rizhao, and Lianyungang) was $305,520,000$ tons (SOA, 2014b). Meanwhile, the sea area with a water quality ranking below the standard of grade I in the Yellow Sea accounted for $10.6 \%$ of the total sea area (NBS and MEP, 2013). The near-shore pollution status is very serious, and routine monitoring in the estuary and bay ecosystems has shown that these areas are impacted by pollution, i.e., in 2014, these ecosystems were ranked as unhealthy or sub-healthy (SOA, 2014a). This study investigated four bays, namely Taozi Bay, Sishili Bay, Dalian Bay, and Jiaozhou Bay, of the Yellow Sea, all of which are surrounded by heavily industrialized and densely populated cities (Yantai, Dalian, and Qingdao). Taozi Bay and Sishili Bay are close to Laizhou Bay (around $200 \mathrm{~km}$ ), which is where the largest manufacturing base of BFRs in Asia is located. These four bays can be classified into three categories according to their relative capacities for seawater exchange with the Yellow Sea in descending order: Taozi Bay $\sim$ Sishili Bay $>$ Dalian Bay $>$ Jiaozhou Bay.

For the present work, surface sediments from four bays in the Yellow Sea were collected and analyzed for PBDEs and aBFRs. The objectives of this study were: (1) to explore the occurrence and spatial distribution of BFRs in coastal surface sediments from the Yellow Sea; (2) to estimate the probable sources of BFRs in the sediments, and (3) to compare the factors that control the spatial distribution of contaminants in these bays, which have different hydrodynamic conditions and terrestrial inputs. To the best of our knowledge, this is the first study to investigate the levels of DBDPE in the coastal sediments of China's Yellow Sea.

\section{Material and methods}

\subsection{Study area}

The geographical locations of the four bays are shown in Fig. 1. Taozi Bay and Sishili Bay are both surrounded by the city of Yantai, which has a population of 1.8 million people in an urban area of $650 \mathrm{~km}^{2}$. Compared to Dalian Bay and Jiaozhou Bay, Taozi Bay and Sishili Bay are relatively open and mainly influenced by coastal currents. The mean water depths of these two bays are $<20 \mathrm{~m}$. Sishili Bay receives nutrients from marine aquaculture operations, wastewater inputs, and harbor pollution (Han and Liu, 2014). Dalian is a major industrial and harbor city with a population of 2.7 million people in an urban area of $2400 \mathrm{~km}^{2}$. Dalian Bay is shallow with a water depth $<30 \mathrm{~m}$. Jiaozhou Bay has a mean water depth of about $7 \mathrm{~m}$ and an area of $438 \mathrm{~km}^{2}$; it is surrounded by Qingdao, which has a population of 4.9 million people in an urban area of $1400 \mathrm{~km}^{2}$. The bay mouth is very narrow (about $2.5 \mathrm{~km}$ ); therefore, it has the lowest capacity for seawater exchange among the four bays. In addition, there are more than 10 small rivers that enter the bay and most of the rivers pass through the urban areas of Qingdao. The largest river entering Jiaozhou Bay is the Dagu River. There is a 

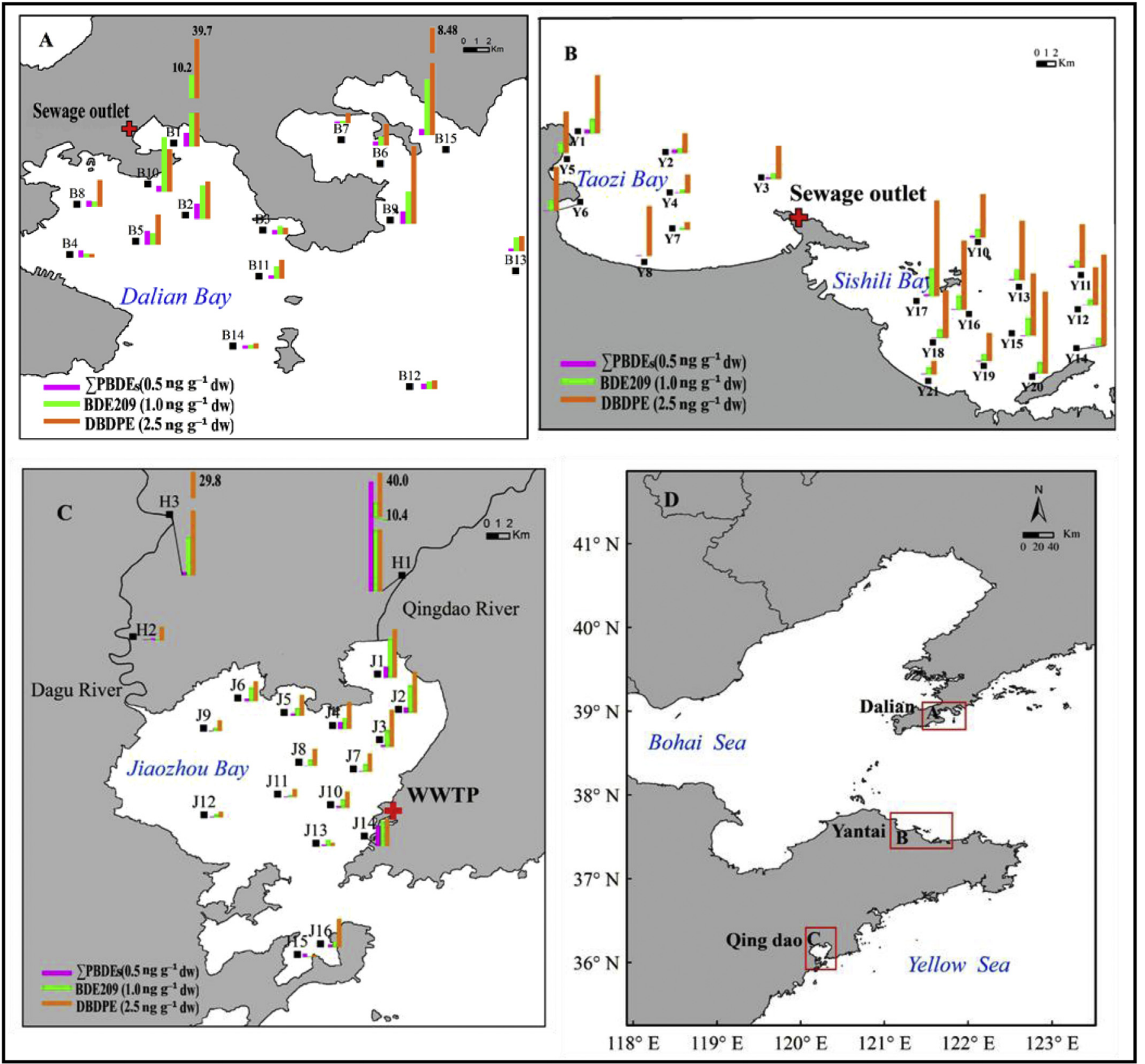

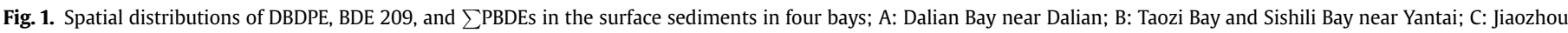
Bay near Qingdao; D: The arrows represent the coastal currents (Zhao et al., 2011).

sewage outlet near the mouth of the Haipo River (Fig. 1C).

\subsection{Sample collection}

Samples were collected from 54 stations (Fig. 1). Of these samples, 36 were collected from Jiaozhou Bay, Taozi Bay, and Sishili Bay in April 2010 (Zhao et al., 2011) and 15 were collected from Dalian Bay in July 2014. Three of the sediment samples collected in April 2010 were obtained from two rivers emptying into Jiaozhou Bay, namely, the Dagu River (site H1) and the Qingdao River (sites H2 and $\mathrm{H} 3)$. About $500 \mathrm{~g}$ surface sediments $(0-5 \mathrm{~cm})$ were collected with a stainless steel grade sampler, and then sealed in clean polyethylene (PE) bags. All sediment samples were stored in a freezer at $-20{ }^{\circ} \mathrm{C}$ until further analysis.

\subsection{Extraction and analysis}

All the samples were freeze-dried, pulverized, homogenized, and Soxhlet extracted by dichloromethane (DCM) extraction for $24 \mathrm{~h}$. Prior to extraction, $20 \mathrm{ng}$ of PCB 209 were added as a surrogate standard, and activated copper and zeolite and were added to the flasks to prevent violent boiling and remove elemental sulfur from the sediment, respectively. The extracts were concentrated to about 2-3 mL by a rotary evaporator. Briefly, concentrated extracts were purified through a $1 \mathrm{~g}$ sodium sulfate and $2.5 \mathrm{~g}$ (10\% deactivated) silica gel column (Möller et al., 2012). The eluting solution consisted of $20 \mathrm{~mL}$ of hexane, and the final extracts were concentrated to approximately $200 \mu \mathrm{L}$ in iso-octane. Before instrumental analysis, $20 \mathrm{ng}$ of an internal standard (PCB 208) were added to the samples. 
Eight aBFRs (PBT, PBEB, HBB, DPTE, TBB, BTBPE, TBPH, and DBDPE), as well as a PBDE standards mixture (BDE 28, 47, 66, 99, 100, 153, 154,183 , and 209), were all purchased from Wellington Laboratories (Guelph, Ontario, Canada). PCB 208 was purchased from AccuStandard (New Haven, CT). All solvents used were redistilled. Neutral silica gel (80-100 mesh) was extracted with DCM for $24 \mathrm{~h}$ and sodium sulfate was baked at $450{ }^{\circ} \mathrm{C}$ for $4 \mathrm{~h}$. The deactivated silica gel and sodium sulfate were sealed in hexane before use.

An Agilent 7890 gas chromatograph (GC) coupled with a 5975C mass selective detector (MSD) in electron capture negative ion chemical ionization mode (ECNICI) was used to identify and quantify the PBDEs and aBFRs. A DB-5MS (30 $\mathrm{m} \times 0.25 \mathrm{~mm}$ i.d., $0.25 \mathrm{~mm}$ film thickness) capillary column was used for the determination of PBDE congeners and aBFRs, except for BDE 209 and DBDPE. A DB-5HT $(15 \mathrm{~m} \times 0.25 \mathrm{~mm}$ ID, $0.1 \mu \mathrm{m}$ film thickness $)$ capillary column was used for separating the BDE 209 and DBDPE. The GC temperature program was set as follows: initially $80^{\circ} \mathrm{C}$ for $2 \mathrm{~min}$, then increased to $200^{\circ} \mathrm{C}$ at $10^{\circ} \mathrm{C} \mathrm{min}^{-1}$ (held for $5 \mathrm{~min}$ ), then to $260{ }^{\circ} \mathrm{C}$ at $10^{\circ} \mathrm{C} \mathrm{min}^{-1}$ (held for $5 \mathrm{~min}$ ), and finally to $310^{\circ} \mathrm{C}$ at $5{ }^{\circ} \mathrm{C} \mathrm{min}^{-1}$ (held for $5 \mathrm{~min}$ ). The injection temperature was $280^{\circ} \mathrm{C}$ and the posting run temperature was $320^{\circ} \mathrm{C}$ for $10 \mathrm{~min}$. The sample injection volume was $1 \mu \mathrm{L}$ and the splitless injection mode was used. The ions 79 and 81 were monitored for BDE 28, 47, 66, 99, 100, 153,154 , and 183 ; ions $\mathrm{m} / \mathrm{z} 463.7,429.7$, and 359.8 for PCB 208; ions $\mathrm{m} / \mathrm{z}$ 497.8, 463.7, and 429.7 for PCB 209; and ions $\mathrm{m} / \mathrm{z} 485$ and 487 for BDE 209.

Prior to the detection of sediment total organic carbon (TOC), carbonates were removed by hydrochloric acid $(\mathrm{HCl})$, and then the TOC concentration was determined with an elemental analyzer (CHNS Vario Ei III, Elementar). The grain size of the surface sediments was analyzed by a laser particle characterization system (Mastersizer 2000, Malvern Instruments, Malvern, UK).

\subsection{Statistical analysis}

The software SPSS 20.0 was used for statistical analyses. Analytical results that were below detection limit were reported as BDL. Correlation analyses were tested by Spearman's rank coefficients. A value of $p<0.05$ was considered significant.

\subsection{Quality assurance and quality control (QA/QC)}

The mean recoveries were $63.5-133.7 \%$ for PCB 209 in the 54 samples. Eleven procedural blanks were analyzed during the extractions, in which BDE 47, BDE 99, and PBT were all detected at low concentrations. The mean recoveries of PCB 209 were 85.3-102.1\% in the solvent blanks. The method detection limits (MDL) were calculated based on the average of the solvent blanks plus three standard deviations of the blanks. The MDLs for PBDEs ranged from 0.004 to $0.44 \mathrm{pg} \mathrm{g}^{-1}$. The MDLs for PBT, PBEB, DPTE, HBB, and DBDPE ranged from 0.004 to $0.03 \mathrm{ng} \mathrm{g}^{-1}, 0.038-0.24 \mathrm{ng} \mathrm{g}^{-1}$, $0.001-0.2 \mathrm{ng} \mathrm{g}^{-1}, 0.57-2.82 \mathrm{ng} \mathrm{g}^{-1}$, and $0.18-3.15 \mathrm{ng} \mathrm{g}^{-1}$, respectively. All the concentrations of PBDEs and aBFRs were not corrected for recovery. For this study, if the values were below the MDL, there were considered not detected (n.d.). In the following sections, $\sum$ PBDEs represents the sum of BDE 28, 47, 66, 99, 100,153, 154 , and 183 , and the $\sum$ aBFRs is the sum of PBT, PBEB, DPTE, and HBB. The $\sum$ PBDEs values of all the samples were above the MDL (except for site Y7) and the three remaining aBFRs (TBB, TBE, and TBPH) were not detected in any coastal sediment samples.

\section{Results and discussion}

\subsection{Concentrations and comparisons with other studies}

Previous studies of BFRs in northern China focused mainly on PBDEs in sediments (Lv et al., 2015; Pan et al., 2011; Wang et al., 2011, 2009; Yang et al., 2004), and no data on levels of aBFRs were found in this area. Table 1 and Table S1 shows the BFRs concentrations in Dalian Bay, Jiaozhou Bay, Taozi Bay, and Sishili Bay along with the concentrations in the two Rivers (Qingdao River and Dagu River) around Jiaozhou Bay. Table 2 compares the levels of BFRs in this study with the values found in other studies. The chemical DBDPE, which is used as a replacement for BDE 209, was detected in all the sediment samples, thus indicating that this contaminant was prevalent in river and marine sediments in northern China. It is note worthy that concentrations of DBDPE in most of the sediments were higher than levels of BDE 209 in this study, and this phenomenon was also seen in other studies of marine, sludge, and sediment samples (Baron et al., 2013; Lee et al., 2014c; Zheng et al., 2015). The concentrations of DBDPE in 51 coastal and 3 river sediment samples ranged from 1.13 to

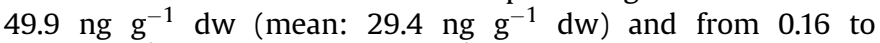
$39.7 \mathrm{ng} \mathrm{g}^{-1} \mathrm{dw}$ (mean: $2.09 \mathrm{ng} \mathrm{g}^{-1} \mathrm{dw}$ ), respectively. The highest level was found in the Qingdao River. In comparison, DBDPE concentrations ( $1.13 \mathrm{ng} \mathrm{g}^{-1} \mathrm{dw}$ at site $\mathrm{H} 1,37.2 \mathrm{ng} \mathrm{g}^{-1} \mathrm{dw}$ at site $\mathrm{H} 2$, and $49.9 \mathrm{ng} \mathrm{g}^{-1} \mathrm{dw}$ at site $\mathrm{H} 3$ ) in the three river sediment samples were one to two orders of magnitude lower than those in the Dongjiang River (n.d. - 1728 ng g $^{-1}$ dw) (Chen et al., 2013), which runs across the major electronic/electrical manufacturing base of the Pearl River Delta (PRD) (Zhang et al., 2015). The DBDPE concentrations (0.16-39.7 $\left.\mathrm{ng} \mathrm{g}^{-1} \mathrm{dw}\right)$ in all coastal sediments in this study were similar to those in the Pearl River estuary (PRE) (n.d. $30.5 \mathrm{ng} \mathrm{g}^{-1} \mathrm{dw}$ ) (Chen et al., 2013) and Ebro and Llobregat River basins (n.d - $31.5 \mathrm{ng} \mathrm{g}^{-1} \mathrm{dw}$ ) (Baron et al., 2014), but higher than those in marine sediments, such as those from the Yangtze River Delta (0.18-1.57 $\mathrm{ng} \mathrm{g}^{-1} \mathrm{dw}$ ) (Zhu et al., 2013), Stockholm coast in Sweden (n.d. - $11 \mathrm{ng} \mathrm{g}^{-1} \mathrm{dw}$ ) (Ricklund et al., 2010), three bays in South America (n.d. - $2.26 \mathrm{ng} \mathrm{g}^{-1} \mathrm{dw}$ ) (Baron et al., 2013), and the western Arctic Ocean (n.d. $-0.45 \mathrm{ng} \mathrm{g}^{-1} \mathrm{dw}$ ) (Cai et al., 2012). The DBDPE concentrations in marine sediments of northern China were at a moderate level, comparatively.

There was no doubt that BDE 209 was the predominate congener of PBDEs found in the samples similar to the data reported in other studies (Kwan et al., 2013; Moon et al., 2012), and it accounted for $90.1 \pm 11.3 \%$ of all the PBDEs congeners detected in all the sediments (except those from site Y8 where BDE 209 was not detected). The detection frequency of BDE 209 in all sediments was $98.0 \%$. Concentrations of BDE 209 in the three river sediment samples $\left(0.05 \mathrm{ng} \mathrm{g}^{-1} \mathrm{dw}\right.$ in site $\mathrm{H} 1,1.94 \mathrm{ng} \mathrm{g}^{-1} \mathrm{dw}$ in site $\mathrm{H} 2$ and $7.82 \mathrm{ng} \mathrm{g}^{-1} \mathrm{dw}$ in site $\mathrm{H} 3$ ) were much lower than those reported for the Dongjiang River (3.83-2517 $\mathrm{ng} \mathrm{g}^{-1} \mathrm{dw}$ ) (Chen et al., 2013), Shanghai River (n.d. -189 ng g $^{-1}$ dw) (Wang et al., 2015b), and Korea' s industrialized bay (2.0-2253 $\mathrm{ng} \mathrm{g}^{-1} \mathrm{dw}$ ) (Moon et al., 2007a). The mean BDE 209 concentration in all the coastal sediments was $0.68 \mathrm{ng} \mathrm{g}^{-1} \mathrm{dw}$ in this study, which was lower than the levels found in other marine sediments of China, such as in the Bohai Sea (2.29 $\mathrm{ng} \mathrm{g}^{-1} \mathrm{dw}$ ) (Wang et al., 2009), East China Sea (6.4 $\mathrm{ng} \mathrm{g}^{-1} \mathrm{dw}$ ) (Li et al., 2012), PRE (14.2 $\mathrm{ng} \mathrm{g}^{-1} \mathrm{dw}$ ) (Chen et al., 2013) and Xiamen offshore area (14.94 $\mathrm{ng} \mathrm{g}^{-1} \mathrm{dw}$ ) (Li et al., 2010); however, the concentration detected in this study was similar to the levels found in the Yangtze River Delta (0.41 $\mathrm{ng} \mathrm{g}^{-1} \mathrm{dw}$ ) (Zhu et al., 2013). High levels of BDE 209 were frequently detected around BFR manufacturing areas, more urbanized cities, and regions with more electrical factories. Compared to coastal sediments in other countries, the ranges of BDE 209 in the 
Table 1

Statistic of concentration of BFRs ( $\mathrm{ng} \mathrm{g}^{-1} \mathrm{dw}$ ) in superficial sediments of four bays, Yellow Sea.

\begin{tabular}{|c|c|c|c|c|c|c|c|c|c|}
\hline \multirow[t]{2}{*}{ Sites } & \multirow[t]{2}{*}{$\mathrm{N}$} & \multicolumn{2}{|l|}{ DBDPE } & \multicolumn{2}{|l|}{$\sum \mathrm{aBFRs}^{\mathrm{a}}$} & \multicolumn{2}{|l|}{ BDE 209} & \multicolumn{2}{|l|}{$\sum \mathrm{PBDEs}^{2}$} \\
\hline & & Range & Mean & Range & Mean & Range & Mean & Range & Mean \\
\hline Dalian Bay & 15 & $0.25-39.7$ & $2.13^{c}$ & $0.002-0.074$ & 0.03 & $0.10-10.2$ & $0.76^{c}$ & $0.02-0.22$ & 0.10 \\
\hline Jiaozhou Bay & 16 & $0.16-4.10$ & 1.74 & n.d. ${ }^{\mathrm{d}}-0.033$ & 0.014 & $0.03-1.99$ & 0.57 & $0.002-0.35$ & 0.064 \\
\hline Taozi Bay & 8 & $0.53-4.15$ & 2.43 & n.d. ${ }^{\mathrm{d}}-0.03$ & 0.01 & n.d. ${ }^{\mathrm{d}}-0.62$ & 0.27 & n.d. ${ }^{c}-0.03$ & 0.02 \\
\hline Sishili Bay & 12 & $0.96-6.49$ & 4.00 & n.d. ${ }^{\mathrm{d}}-0.09$ & 0.02 & $0.25-1.18$ & 0.47 & $0.004-0.02$ & 0.01 \\
\hline River & 3 & $1.13-49.9$ & 29.4 & $0.02-1.05$ & 0.61 & $0.05-7.82$ & 3.27 & $0.03-1.85$ & 0.65 \\
\hline
\end{tabular}

a Sum of PBT, PBEB, DPTE, and HBB.

b Sum of BDE 28, 47, 66, 99, 100, 153, 154, and 183.

c Average concentrations of DBDPE or BDE 209 in Dalian Bay (excluding site B1).

d Not detected.

Table 2

Comparison BFR concentrations ( $\mathrm{ng} \mathrm{g}^{-1} \mathrm{dw}$ ) in surface sediments of this study with concentrations measured in other studies.

\begin{tabular}{|c|c|c|c|c|c|c|}
\hline Sites & Sampling year & DBDPE & $\sum \mathrm{aBFRs}^{\mathrm{a}}$ & BDE 209 & $\sum \mathrm{PBDEs}^{\mathrm{b}}$ & Reference \\
\hline Four bays ${ }^{\mathrm{d}}$, Yellow Sea in North China & 2010-2014 & n.d.-39.7 (2.96) & n.d-0.85 (0.02) & n.d.-10.2 (0.64) & n.d. $-0.35(0.05)$ & This study \\
\hline River, Jaozhou Bay in North China & 2010 & $1.13-49.9(29.4)$ & $0.02-1.05(3.27)$ & $0.05-7.82(0.65)$ & $0.03-1.85(0.37)$ & This study \\
\hline Dalian coastal area, North China & 2008 & & $0.073-1.9(0.33)$ & $3.94-103(25.0)$ & $0.016-1.33(0.29)$ & (Wang et al., 2011) \\
\hline Bo Sea, North China & 2006 & & & $0.30-2776(2.29)^{c}$ & $0.07-5.24(0.16)^{c}$ & (Wang et al., 2009) \\
\hline Laizhou Bay, North China & 2009 & & & $0.66-12(5.1)$ & n.d. $-0.60(0.32)$ & (Pan et al., 2011) \\
\hline Jiaozhou Bay, North China & 1997-1999 & & & & $0.12-5.51(1.38)^{\mathrm{e}}$ & (Yang et al., 2004) \\
\hline Yangtze River Delta, East China & 2011 & $0.18-1.6(0.47)$ & $(<0.98)$ & $0.04-1.26(0.41)$ & $0.94-0.96(0.96)$ & (Zhu et al., 2013) \\
\hline The coastal East China Sea (ECS) & $2006-2007$ & & & $0.30-44.6(6.4)$ & n.d. -8.0 & (Li et al., 2012) \\
\hline Pearl River Estuary (PRE), South China & 2009-2010 & n.d. $-30.5(10.2)$ & $0.09-1.98(0.47)$ & $(14.2)$ & $3.67-45.6(17.1)^{\mathrm{e}}$ & (Chen et al., 2013) \\
\hline Xiamen Offshore Areas, South China & 2007 & & & $0.10-70.11(14.9)$ & $0.17-6.43(1.37)$ & (Li et al., 2010) \\
\hline Hong Kong, South China & 2004 & & & n.d.-2.92 & $1.7-53.6^{\mathrm{e}}$ & (Liu et al., 2005) \\
\hline Tokyo Bay, Japan & 2002 & & & $0.89-18$ & $0.06-0.78$ & (Minh et al., 2007) \\
\hline Goseong Bay, Korea & 2011 & & & $0.03-11.4$ & $0.02-2.65$ & (Lee et al., 2014a) \\
\hline San Francisco Bay, USA & 2007 & & $0.01-0.02$ & $(1.00-5.00)$ & $2-8(4)$ & (Klosterhaus et al., 2012) \\
\hline Three bays ${ }^{\mathrm{f}}$, South America & $2009-2010$ & n.d. -2.26 & n.d. -0.11 & n.d. -1.72 & n.d. -1.57 & (Baron et al., 2013) \\
\hline Western Arctic Ocean & 2008 & n.d. -0.45 & & n.d. $-0.80(0.11)$ & $0.004-0.15(0.04)$ & (Cai et al., 2012) \\
\hline Stockholm coast, Sweden & 2008 & n.d.-11 & & n.d. -88 & & (Ricklund et al., 2010) \\
\hline
\end{tabular}

n.d. Not detect.

a Sum of all the aBFRs concentrations, including PBT, PBEB, DPTE, and HBB.

b Sum of all the PBDE congeners (excluding BDE 209).

c Median concentration.

d Dalian Bay, Jaozhou Bay, Taozi Bay, and Sishili Bay.

e Sum of all the PBDE congener concentrations (including BDE 209).

f San Vicenta bay, Coronel Bay, and Conceción Bay.

four bays of this study (n.d. $-10.2 \mathrm{ng} \mathrm{g}^{-1} \mathrm{dw}$ ) were lower than those in Tokyo Bay (0.89-18 $\mathrm{ng} \mathrm{g}^{-1} \mathrm{dw}$ ) (Minh et al., 2007) and the Stockholm coast in Sweden (n.d. $-88 \mathrm{ng} \mathrm{g}^{-1} \mathrm{dw}$ ) (Ricklund et al., 2010). In addition, Goseong Bay, which is located in a rural area of Korea, showed similar BDE 209 concentrations to the ones found in the study region of this work (Lee et al., 2014b). The ranges of BDE 209 concentrations in this study were higher than those detected in three bays from South America and in the western Arctic Ocean (Table 2). However, the concentrations of BDE 209 in this study were lower than those detected in other coastal areas of China during previous studies (Wang et al., 2011; Yang et al., 2004).

Compared with other studies on coastal and marine sediments in China (Table 2), relatively low concentrations of $\sum$ PBDEs (mean $0.09 \mathrm{ng} \mathrm{g}^{-1} \mathrm{dw}$ ) and $\sum$ aBFRs (mean $0.02 \mathrm{ng} \mathrm{g}^{-1} \mathrm{dw}$ ) were observed in this study. Among the aBFRs, PBT and DPTE were the most common compounds, and the corresponding detection frequencies were over $60 \%$ in all the marine sediments. The compounds TBE, TBB, and TBPH were observed only at low concentration in the Qindao River and Dagu River sediments. The concentrations of $\sum$ PBDEs and $\sum$ aBFRs ranged from 0.03 to $1.85 \mathrm{ng} \mathrm{g}^{-1} \mathrm{dw}$ and from 0.02 to $1.05 \mathrm{ng} \mathrm{g}^{-1} \mathrm{dw}$ in river sediments, respectively. Syed et al. (2013) reported levels of PBDEs in Pakistan's Ravi River ranging from n.d. to $15 \mathrm{ng} \mathrm{g}^{-1} \mathrm{dw}$. Moreover, Chen et al. (2013) reported the ranges of three BFRs (PBT, PBEB, and HBB) in the Dongjiang River and Zhujiang River, and both sites had higher levels than those detected in the two rivers evaluated in this study. As for coastal sediments, concentrations varied from n.d. to $0.35 \mathrm{ng} \mathrm{g}^{-1} \mathrm{dw}$ for $\sum$ PBDEs and from n.d. to $0.09 \mathrm{ng} \mathrm{g}^{-1} \mathrm{dw}$ for $\sum$ aBFRs. The levels of $\sum$ PBDEs and PBEB in this study were similar to those in the Dalian coastal area (Wang et al., 2011), three bays from South America (Baron et al., 2013) and the western Arctic Ocean (Cai et al., 2012).

\subsection{Spatial distribution of BFRs in the four bays}

As the DBDPE concentration in site B1 (39.7 $\mathrm{ng} \mathrm{g}^{-1} \mathrm{dw}$ ) was higher than the sum of the remaining 14 sites in Dalian Bay (29.8 $\mathrm{ng} \mathrm{g}^{-1} \mathrm{dw}$ ), the average DBDPE level (2.13 $\mathrm{ng} \mathrm{g}^{-1} \mathrm{dw}$ ) reported for Dalian Bay represents only the 14 samples (excluding site B1). Relative mean DBDPE concentrations at the study sites, in descending order, were as follows: rivers > Sishili Bay > Taozi Bay > Dalian Bay (excluding site B1) > Jiaozhou Bay (Table 1).

Jiaozhou Bay is a nearly enclosed bay relative to the other three bays, and the capacity of seawater exchange with the outside Yellow Sea is weak in this region; hence, direct discharge from human activities might be an important factor controlling the DBDPE distributions in Jiaozhou Bay. The concentrations of DBDPE together with BDE 209 and $\sum$ PBDEs in eastern Jiaozhou Bay were higher than those in the western and northern parts of this bay, and the highest level of DBDPE was found at site H1, which is close to the estuary of the Qingdao River (Fig. 1C). First, in eastern Jiaozhou Bay, 
several rivers (including the Qingdao River, Baisha River, and Haipo River) run through industrial and residential regions, and this likely leads to contaminant discharge into the bay via the rivers. However, the Dagu River is located in northwestern Jiaozhou Bay and the water discharge volume of this river into Jiaozhou Bay is higher than that for the other rivers mentioned above. The relative DBDPE concentrations of the three sediment samples from the Dagu River estuary in descending order were as follows: $\mathrm{H} 3>\mathrm{H} 2>\mathrm{J} 12$. This indicates that the Dagu River was not a major contributor of BFRs to Jiaozhou Bay. This is reasonable as the western Dagu River flows mainly through agricultural areas.

There are WWTPs in east Jiaozhou Bay and northeast Sishili Bay. The concentrations of DBDPE decreased with increases in the distance from the outlets of the WWTPs in these two bays, and the value of DBDPE at site J14 was higher than that detected at sites J10 and J12 in Jiaozhou Bay (Fig. 1C). Yang et al. (2004) also reported that the highest level of PBDEs was observed near site J14. Dalian Bay is a semi-closed bay where the distributions of DBDPE are complex. Wang et al. (2011) stated that there are approximately 50 sewage outlets distributed evenly around Dalian Bay and these sewage outlets play an important role in the PBDEs pollution of this area. The highest level of DBDPE was observed at site B1, which is in the lower reaches of a sewage outlet area, and the DBDPE concentrations decreased with increases in the distances from shore for most of the stations in Dalian Bay (Fig. 1A), thus implying that the sewage outlets might be sources for the DBDPE. This is coincident with the fact that DBDPE was the most dominant BFR in the sewage sludge samples from 62 WWTPs in China (Zeng et al., 2014).

Both Taozi Bay and Sishili Bay are surrounded by the city of Yantai. While there are WWTPs and harbors in all four bays, higher levels of DBDPE were detected in Taozi Bay and Sishili Bay. The reasons for this may be ascribed to the hydrodynamics of seawater and the regional sources. Generally, Sishili Bay and Taozi Bay are both open bays in which ocean currents likely play a significant role in the spatial distribution of DBDPE, and notably the biggest manufacturing base of BFRs in China is located around Laizhou Bay, which is close to these two bays (Pan et al., 2011). Higher levels of DBDPE compared to BDE 209 were found during a gridded passive air sampling project in Laizhou Bay and its neighboring region (Zhao et al., 2013b). It was stated that suspended sediment originated from the Yellow River can transport through the Laizhou Bay, Bohai Strait, and Northern Shandong Peninsula to the South Yellow Sea by alongshore current (Yang and Liu, 2007); Zhao et al. (2011) reported that Dechlorane Plus, a polychlorinated flame retardant, from within Laizhou Bay (around the BFRs manufacturing base) can be transported to Sishili Bay and Taozi Bay through coastal currents. In addition, the ranges of BDE 209 concentrations (0.30-2776 $\mathrm{ng} \mathrm{g}^{-1} \mathrm{dw}$, with a median of $\left.2.29 \mathrm{ng} \mathrm{g}^{-1} \mathrm{dw}\right)$ in the coastal sediments of Bohai Sea (Wang et al., 2009) were one magnitudes higher than those in Sishili Bay $\left(0.25-1.18 \mathrm{ng} \mathrm{g}^{-1} \mathrm{dw}\right.$, with a mean of $0.47 \mathrm{ng} \mathrm{g}^{-1} \mathrm{dw}$ ) and Taozi Bay sediments (n.d. $0.62 \mathrm{ng} \mathrm{g}^{-1} \mathrm{dw}$, with a mean of $0.47 \mathrm{ng} \mathrm{g}^{-1} \mathrm{dw}$ ). This is additional evidence that the currents affect the BDE 209 distribution in the sediments of these two bays. Furthermore, the relative standard deviations of DBDPE in the two bays ( 0.48 and 0.44 in Taozi Bay and Sishili Bay, respectively) were lower than those in the other two bays (1.04 and 0.64 in Dalian Bay and Jiaozhou Bay, respectively), and this was likely because the good level of seawater exchange gave the contaminants a chance to mix well.

Previous studies have demonstrated that TOC and grain size can affect the distribution of POPs (Zhao et al., 2010; Zheng et al., 2011). Among the investigated areas, a good correlation between TOC and $\operatorname{DBDPE}(\mathrm{r}=0.61 ; p<0.05$, Table S2a-d) was only found in Jiaozhou Bay. Furthermore, a very weak correlation was found between the median diameter (MD) of the grain size and DBDPE in all the sediments. Hence, the TOC might have affected the DBDPE distribution in this bay. In the other three bays where poor correlations between DBDPE and TOC were detected, a combination of factors such as local sources, atmospheric deposition, and tide-induced water exchange may have played a key role in the contaminant distribution.

The highest levels of BDE 209 were observed in Dalian Bay, followed in order by Jiaozhou Bay, Sishili Bay, and Taozi Bay (Table 1). In Dalian City, the electronics industry was booming in the 1980s and this is when BDE 209 was the predominant flame retardant in use. In addition, the population of Dalian is about 6.7 million people and a variety of industrial, port related, and shipping activities take place in this bay. The ranges of concentrations of BDE 209 (3.94-103 $\mathrm{ng} \mathrm{g}^{-1} \mathrm{dw}$ ) reported by Wang et al. (2011) were one order of magnitude higher than those from this study in the same area. Higher usage of DecaBDE in this region in the past and historical residues might be significant factors for the high mean levels of BDE 209 and PBDEs found in Dalian Bay. The highest level of BDE 209 in coastal sediments was observed at site B1 (10.2 $\left.\mathrm{ng} \mathrm{g}^{-1} \mathrm{dw}\right)$, which coincided with the distribution of DBDPE. Fig. 2 shows the correlations between DBDPE and BDE 209 concentrations in each bay, and the distributions of DBDPE were similar to those of BDE 209. These compounds likely displayed similar environmental behaviors because of their structural similarities.

$\sum$ PBDEs distributions are shown in Fig. 1. A good correlation was observed between $\sum$ PBDEs and BDE 209 in Dalian Bay $(\mathrm{r}=0.53, p<0.05$, Table S2a) and Jiaozhou Bay $(\mathrm{r}=0.66, p<0.01$, Table S2b), but the results were not significant in Taozi Bay and Sishili Bay. This finding could have been due to more complex source contributions for PBDEs in the latter two bays. Wang et al. (2011) demonstrated that direct input of effluent from sewage outlets was the source of BFRs in Dalian Bay. Hence, local inputs might have influenced the distribution of $\sum$ PBDEs in this coastal bay.

In summary, BFRs concentrations were highest near the river mouths, WWTPs, and sewage outlets in Jiaozhou Bay and Dalian Bay. As for the distribution of BFRs in Sishili Bay and Taozi Bay, the coastal currents had a large influence on the contaminant distribution. Other factors such as regional usage variability, TOC, and atmospheric deposition might have also played a significant role in the BFR distributions in these study areas.

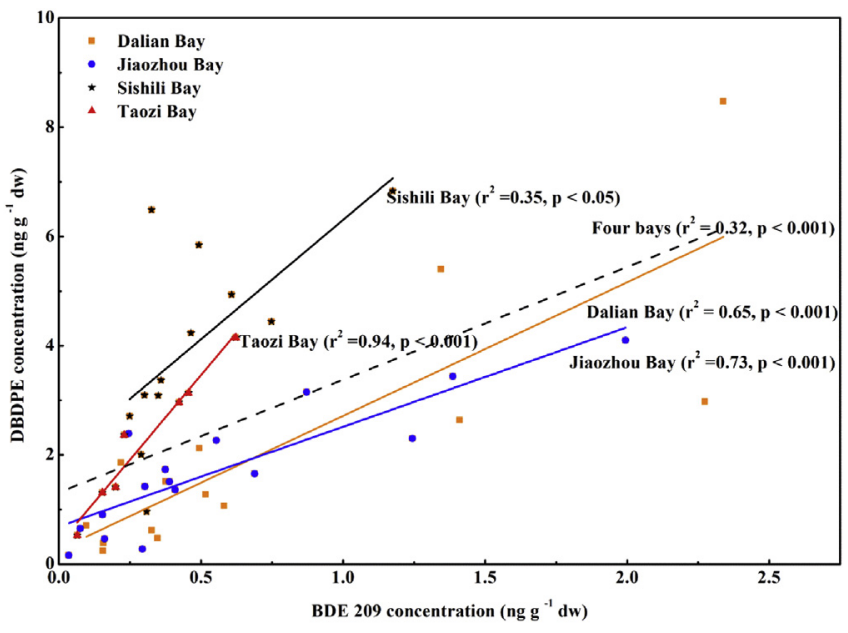

Fig. 2. Correlations between BDE 209 and DBDPE concentrations in four bays, including Dalian Bay, Jiaozhou Bay, Sishili Bay, and Taozi Bay; Dash line represents the correlation between DBDPE and BDE 209 in all the coastal sediments. 


\subsection{Compositional features of BFRs among the four bays}

Fig. 3 shows the composition of BFRs in coastal sediments of the four bays. In the study area, DBDPE was the predominant compound detected, with mean contributions of $89.1 \%, 88.7 \%, 70.7 \%$ and $72.7 \%$ for Taozi Bay, Sishili Bay, Dalian Bay, and Jiaozhou Bay, respectively. BDE 209 also contributed relatively large proportions to the total BFRs (8.5-29.1\% on average). This chemical, BDE 209, was the predominant congener of the eight PBDEs analyzed in this study, which is consistent with results from other studies on soil, sediment, and air samples in China (Chen et al., 2012; Hu et al., 2010; Zhao et al., 2013a). This could be due to the fact that commercial deca-BDE accounts for most of the total PBDE mixture production and usage in China (Chen et al., 2012). The contributions of $\sum$ PBDEs $(0-22.2 \%)$ and $\sum$ aBFRs $(0-1.0 \%)$ to the total BFRs in the four bays were much lower than those of DBDPE and BDE 209. Chen et al. (2013) mentioned that the production volume of commercial DBDPE in China was estimated to be 12,000 tons in 2006, while the production volume of commercial decaBDE was 15,000 tons in 2006 (Zhao et al., 2013a). Presently, these numbers are likely much higher because of the phase out of deca-BDE in Europe and North America, which shifted the production to China. Hence, extensive production of DBDPE and BDE 209 could have been responsible for the profile patterns detected in this study.

The average ratios of DBDPE/BDE209 in sediments from Dalian Bay, Jiaozhou Bay, Taozi Bay, the two river sites, and Sishili Bay were 3.4, 4.1, 7.8 (excluding site Y7), 9.0, and 9.2, respectively. This finding is likely a result of the regional variability in BFRs usage. Except for sediments, similar high ratios have been observed in other environmental media in China, for example, 4.0 (on average) for soil samples (Zheng et al., 2015) and 2.8 (on average) for air samples (Zhao et al., 2013a). Therefore, contamination of DBDPE exceeding that of BDE 209 in some environmental matrices in China appears to be a common occurrence.

As shown in Fig. 4, percentages of $\sum$ PBDEs varied at all sampling sites except site Y7, where the $\sum$ PBDEs were below the detection limit. The compounds BDE 28 and BDE 47 were the dominant congeners in Taozi Bay ( $59.1 \pm 29.2 \%$ and $27.3 \pm 20.4 \%$, respectively) and Sishili Bay $(46.9 \pm 25.2 \%$ and $55.6 \pm 24.2 \%$, respectively). Furthermore, at sites Y5, Y8, and Y21 (all are very close to the shoreline), BDE 28 was the only congener above the detection limit. Some heavier BDE congeners (BDE 100,153, and 154) were below the detection limit in Taozi Bay and Sishili Bay. This was likely because the heavier BDE congeners degraded to BDE 47 and BDE 28 after they were released to the environment. Meanwhile, both BDE 28 and BDE 47 are more volatile than the heavier congeners; therefore, their high proportions in Taozi Bay and Sishili Bay may have also stemmed from coastal current transport, LRAT, and air deposition.

Compared with the two bays mentioned above, the composition pattern of $\sum$ PBDEs in Dalian Bay was more complicated (Fig. 4), as all the target $\mathrm{BDE}$ congeners were detected in this area. The relative abundance of $\sum$ PBDEs decreased in the following order: BDE $99>$ BDE $47>$ BDE $183>$ BDE $153>$ BDE $28>$ BDE $154>$ BDE $100 \sim$ BDE 66. This pattern was similar to those found in the Zhujiang and Dongjiang Rivers (except for BDE 28) (Mai et al., 2005), where the environment is greatly influenced by electronic industrial activities. The compounds BDE 99 (45.8 $\pm 14.8 \%)$ and BDE 47 $(21.4 \pm 7.0 \%)$ were the two most abundant BDE congeners found in Dalian Bay. The mean ratio of BDE $47 /($ BDE $47+$ BDE 99) in sediments (0.32) of Dalian Bay was lower than the value for DE-71 (0.44) and 70-5DE (0.49) (La guardia et al., 2006), which are both commercial penta-BDE products; this implies that the different formulas of BDE products are used in Dalian (i.e., not DE-71 or 705DE). By comparison, BDE153 and BDE 154 comprised $1.2-26.2 \%$ of $\sum$ PBDEs in sediments of Dalian Bay, with a mean value of $11.7 \%$. The compounds BDE 183, which is a major component of octa-BDE mixtures, accounted for $0-33.5 \%$ of $\sum$ PBDEs, with a mean value of $14.8 \%$.

In Jiaozhou Bay, the predominant BDE congeners were BDE 47 $(41.2 \pm 33.6 \%)$ and BDE $99(26.1 \pm 22.4 \%)$. However, in the riverine samples, BDE 47 was detected only at site H1 (Qingdao River) at a low proportion of $3.4 \%$. BDE 153 was detected at higher proportions in the rivers $(16.2 \pm 14.4 \%)$ than in Jiaozhou Bay $(5.0 \pm 11.8 \%)$. The $\sum$ PBDEs congener pattern in Jiaozhou Bay was significantly different $(p>0.05)$ from those in the two rivers, thus implying that the rivers were not a notable source for the lower brominated BDE congeners.

In this study, the seven BDE congeners were well correlated $\left(r^{2}>0.24\right.$ between six BDE congeners excluding BDE 100) with each

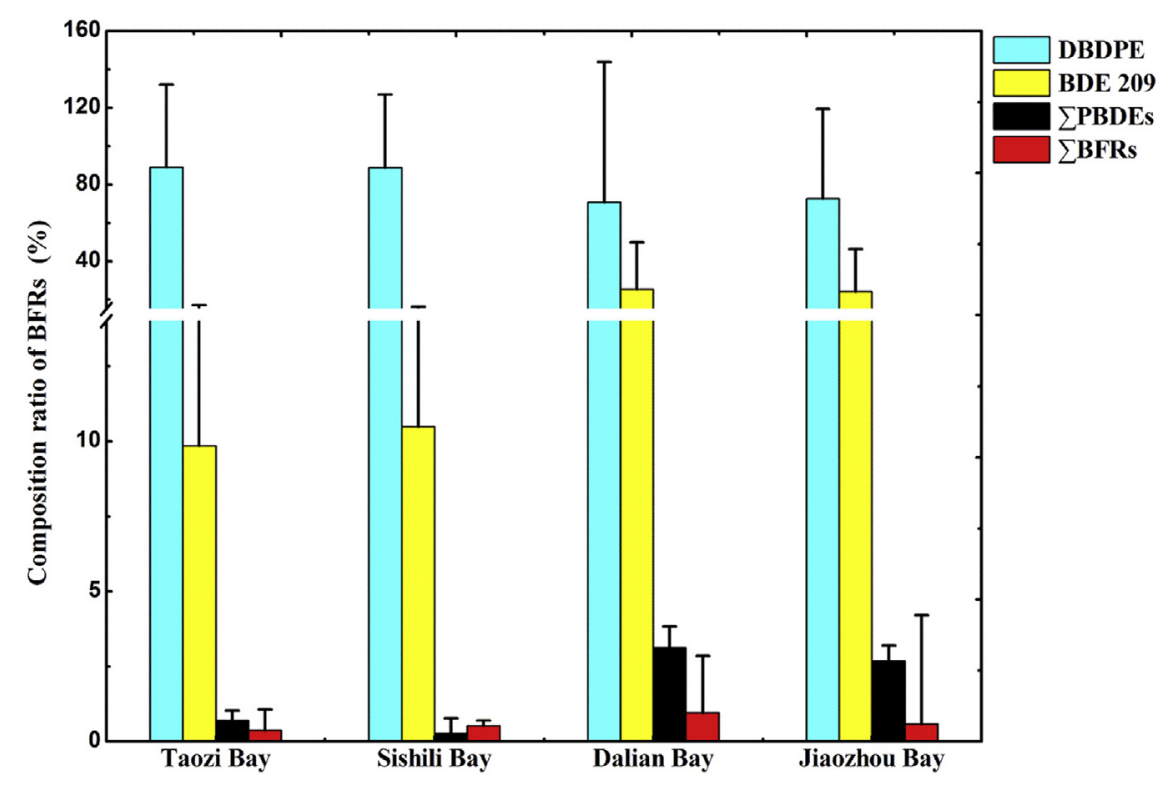

Fig. 3. Composition ratio of BFRs (DBDPE, BDE 209, $\sum$ PBDEs, and $\sum$ aBFRs) in all sediments in four bays (Taozi Bay, Sishili Bay, Dalian Bay, and Jiaozhou Bay). 


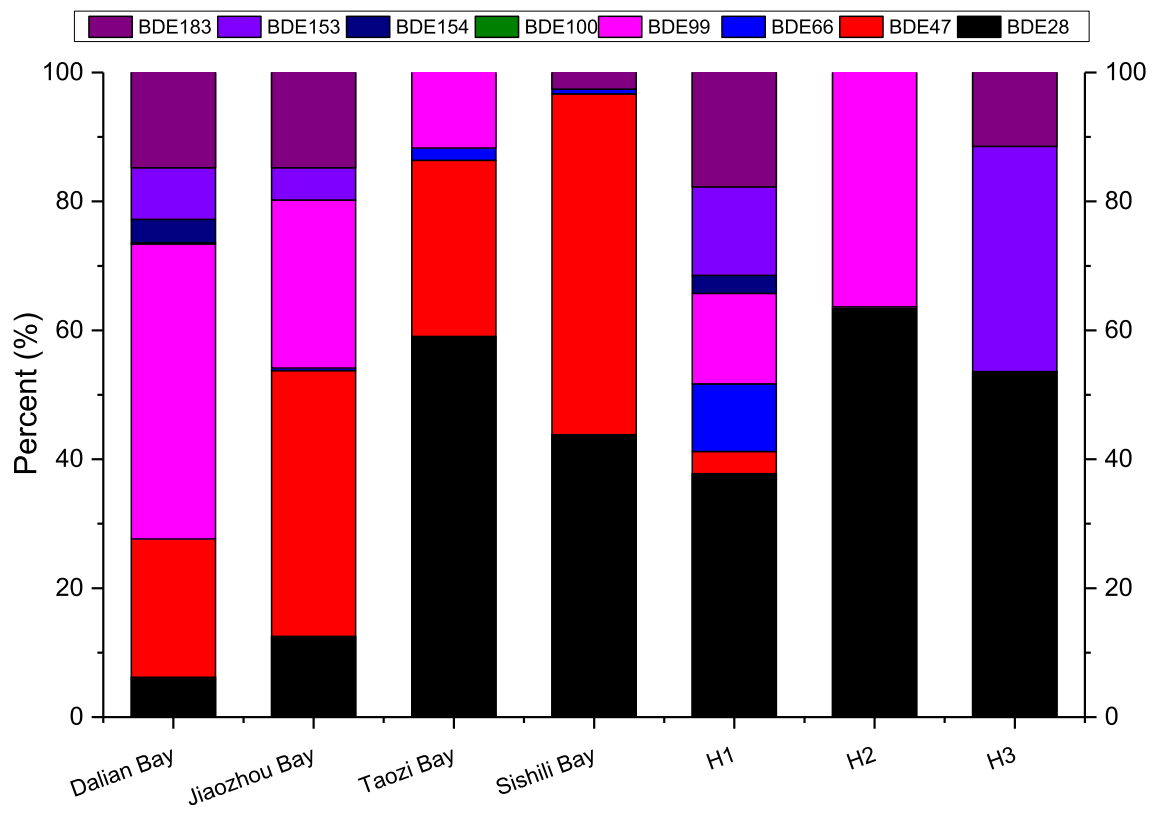

Fig. 4. Mean congener contributions of $\sum$ PBDEs in sediments of the four bays and rivers.

other in all the sediments. The correlation was especially good between BDE 209 and $\sum$ PBDEs, thus demonstrating that the degradation of highly brominated $\mathrm{BDE}$ congeners might be the source for the lower brominated BDE congeners in this study area.

\section{Conclusion}

This study determined the levels of BFRs, such as DBDPE, BDE $209, \sum$ PBDEs, and $\sum$ aBFRs, in four typical coastal bays in the Yellow Sea of China. The DBDPE concentration exceeded that of BDE 209 in nearly all the sediment samples (excluding site J13) and was at a moderate level compared to the levels measured in other studies of marine sediments from China. The ratios of DBDPE/BDE 209 varied slightly within, but largely among, the four bays. The levels of BFRs in Jiaozhou Bay decreased with increasing distances from the river mouths and sewage outlets, which drain pollution from the urban area of Qingdao. Meanwhile, the highest levels of DBDPE and BDE 209 were found around the sewage outlets in Dalian Bay. These findings suggest that point sources from rivers and sewage outlets might be the main sources for BFRs in these two bays. For the relatively open bays, Sishili Bay and Taozi Bay, higher levels of DBDPE and BDE 209 were found in the outer bay areas rather than in the inner bay areas. Transportation by coastal currents from the nearby Laizhou Bay area combined with local source inputs were deemed to be the major sources of BFRs in these two bays. Degradation of higher brominated BDE congeners, atmospheric transport, and deposition might have been responsible for the distribution of low brominated BDE congeners in these bays.

\section{Acknowledgments}

This work was supported by the Key Research Programs of the Chinese Academy of Sciences (XDA11020401, KZZD-EW-14, 13337KYSB20130013, and 2013T2Z0032). The authors thank all the staff and students for their assistance during sampling campaign and laboratory work.

\section{Appendix A. Supplementary data}

Supplementary data related to this article can be found at http:// dx.doi.org/10.1016/j.envpol.2016.02.042.

\section{References}

Baron, E., Gago-Ferrero, P., Gorga, M., Rudolph, I., Mendoza, G., Zapata, A.M., DiazCruz, S., Barra, R., Ocampo-Duque, W., Paez, M., Darbra, R.M., Eljarrat, E., Barcelo, D., 2013. Occurrence of hydrophobic organic pollutants (BFRs and UVfilters) in sediments from South America. Chemosphere 92, 309-316.

Baron, E., Santin, G., Eljarrat, E., Barcelo, D., 2014. Occurrence of classic and emerging halogenated flame retardants in sediment and sludge from Ebro and Llobregat river basins (Spain). J. Hazard Mater. 265, 288-295.

BSEF, 2015. Regulation on BFRs.

Cai, M.G., Hong, Q.Q., Wang, Y., Luo, X.J., Chen, S.J., Cai, M.H., Qiu, C.R., Huang, S.Y., Mai, B.X., 2012. Distribution of polybrominated diphenyl ethers and decabromodiphenylethane in surface sediments from the Bering Sea, Chukchi Sea, and Canada Basin. Deep Sea Res. Part II Top. Stud. Oceanogr. 81-84, 95-101.

Chen, C., Zhao, H., Chen, J., Qiao, X., Xie, Q., Zhang, Y., 2012. Polybrominated diphenyl ethers in soils of the modern Yellow River Delta, China: occurrence, distribution and inventory. Chemosphere 88, 791-797.

Chen, S.J., Feng, A.H., He, M.J., Chen, M.Y., Luo, X.J., Mai, B.X., 2013. Current levels and composition profiles of PBDEs and alternative flame retardants in surface sediments from the Pearl River Delta, southern China: comparison with historical data. Sci. Total Environ. 444, 205-211.

Covaci, A., Harrad, S., Abdallah, M.A., Ali, N., Law, R.J., Herzke, D., de Wit, C.A., 2011. Novel brominated flame retardants: a review of their analysis, environmental fate and behaviour. Environ. Int. 37, 532-556.

Fang, Y., Chen, Y., Tian, C., Lin, T., Hu, L., Huang, G., Tang, J., Li, J., Zhang, G., 2015. Flux and budget of $\mathrm{BC}$ in the continental shelf seas adjacent to Chinese high $\mathrm{BC}$ emission source regions. Glob. Biogeochem. Cycles 29, 957-972.

Han, Q., Liu, D., 2014. Temporal and spatial variations in the distribution of macroalgal communities along the Yantai coast, China. Chin. J. Oceanol. Limnol. 32, 595-607.

Hu, G., Xu, Z., Dai, J., Mai, B., Cao, H., Wang, J., Shi, Z., Xu, M., 2010. Distribution of polybrominated diphenyl ethers and decabromodiphenylethane in surface sediments from Fuhe River and Baiyangdian Lake, North China. J. Environ. Sci. 22, 1833-1839.

Klosterhaus, S.L., Stapleton, H.M., La Guardia, M.J., Greig, D.J., 2012. Brominated and chlorinated flame retardants in San Francisco Bay sediments and wildlife. Environ. Int. 47, 56-65.

Kwan, C.S., Takada, H., Mizukawa, K., Saha, M., Rinawati, Santiago, E.C., 2013. Sedimentary PBDEs in urban areas of tropical Asian countries. Mar. Pollut. Bull. 76, 95-105.

La guardia, M.J., Hale, R.C., Harvey, E., 2006. Detailed polybrominated diphenyl ether (PBDE) congener composition of the widely used penta-, octa-, and deca PBDE technical flame-retardant mixtures. Environ. Sci. Technol. 40, 6247-6254.

Lee, C.-H., Lee, B.-Y., Chang, W.K., Hong, S., Song, S.J., Park, J., Kwon, B.-O., Khim, J.S., 
2014a. Environmental and ecological effects of Lake Shihwa reclamation project in South Korea: a review. Ocean Coast. Manag. 102, 545-558.

Lee, H.J., An, S., Kim, G.B., 2014b. Background level and composition of polybrominated diphenyl ethers (PBDEs) in creek and subtidal sediments in a rural area of Korea. Sci. Total Environ. 470-471, 1479-1484.

Lee, S., Song, G.J., Kannan, K., Moon, H.B., 2014c. Occurrence of PBDEs and other alternative brominated flame retardants in sludge from wastewater treatment plants in Korea. Sci. Total Environ. 470-471, 1422-1429.

Li, J., Li, Q., Gioia, R., Zhang, Y., Zhang, G., Li, X., Spiro, B., Bhatia, R.S., Jones, K.C., 2011 PBDEs in the atmosphere over the Asian marginal seas, and the Indian and Atlantic oceans. Atmos. Environ. 45, 6622-6628.

Li, Q., Yan, C., Luo, Z., Zhang, X., 2010. Occurrence and levels of polybrominated diphenyl ethers (PBDEs) in recent sediments and marine organisms from Xiamen offshore areas, China. Mar. Pollut. Bull. 60, 464-469.

Li, Y., Lin, T., Chen, Y., Hu, L., Guo, Z., Zhang, G., 2012. Polybrominated diphenyl ethers (PBDEs) in sediments of the coastal East China Sea: occurrence, distribution and mass inventory. Environ. Pollut. 171, 155-161.

Lin, Y., Qiu, X., Zhao, Y., Ma, J., Yang, Q., Zhu, T., 2013. Polybromobenzene pollutants in the atmosphere of North China: levels, distribution, and sources. Environ. Sci. Technol. 47, 12761-12767.

Liu, Y., Zheng, G.J., Yu, H., Martin, M., Richardson, B.J., Lam, M.H., Lam, P.K., 2005. Polybrominated diphenyl ethers (PBDEs) in sediments and mussel tissues from Hong Kong marine waters. Mar. Pollut. Bull. 50, 1173-1184.

Lv, J., Zhang, Y., Zhao, X., Zhou, C., Guo, C., Luo, Y., Meng, W., Zou, G., Xu, J., 2015. Polybrominated diphenyl ethers (PBDEs) and polychlorinated biphenyls (PCBs) in sediments of Liaohe River: levels, spatial and temporal distribution, possible sources, and inventory. Environ. Sci. Pollut. Res. Int. 22, 4256-4264.

Möller, A., Xie, Z., Caba, A., Sturm, R., Ebinghaus, R., 2012. Occurrence and airseawater exchange of brominated flame retardants and Dechlorane Plus in the North Sea. Atmos. Environ. 46, 346-353.

Ma, X., Zhang, H., Yao, Z., Zhao, X., Wang, L., Wang, Z., Chen, J., Chen, J., 2013. Bioaccumulation and trophic transfer of polybrominated diphenyl ethers (PBDEs) in a marine food web from Liaodong Bay, North China. Mar. Pollut. Bull. 74, $110-115$.

Mai, B., Chen, S., Luo, X., Chen, L., Yang, Q., Sheng, G.Y., Peng, P., Fu, J.M., Zeng, E., 2005. Distribution of polybrominated diphenyl ethers in sediments of the Pearl River Delta and adjacent South China Sea. Environ. Sci. Technol. 39, 7.

Minh, N.H., Isobe, T., Ueno, D., Matsumoto, K., Mine, M., Kajiwara, N., Takahashi, S., Tanabe, S., 2007. Spatial distribution and vertical profile of polybrominated diphenyl ethers and hexabromocyclododecanes in sediment core from Tokyo Bay, Japan. Environ. Pollut. 148, 409-417.

Moller, A., Xie, Z., Sturm, R., Ebinghaus, R., 2011. Polybrominated diphenyl ethers (PBDEs) and alternative brominated flame retardants in air and seawater of the European Arctic. Environ. Pollut. 159, 1577-1583.

Moon, H.B., Choi, M., Yu, J., Jung, R.H., Choi, H.G., 2012. Contamination and potential sources of polybrominated diphenyl ethers (PBDEs) in water and sediment from the artificial Lake Shihwa, Korea. Chemosphere 88, 837-843.

Moon, H.B., Kannan, K., Choi, M., Choi, H.G., 2007a. Polybrominated diphenyl ethers (PBDEs) in marine sediments from industrialized bays of Korea. Mar. Pollut. Bull. 54, 1402-1412.

Moon, H.B., Kannan, K., Lee, S.J., Choi, M., 2007b. Polybrominated diphenyl ethers (PBDEs) in sediment and bivalves from Korean coastal waters. Chemosphere 66, $243-251$.

NBS, MEP, 2013. China Statistical Yearbook on Environment 2013. China Stastics Press, Beijing.

Pan, J., Yang, Y.L., Xu, Q., Chen, D.Z., Xi, D.L., 2007. PCBs, PCNs and PBDEs in sediments and mussels from Qingdao coastal sea in the frame of current circulations and influence of sewage sludge. Chemosphere 66, 1971-1982.

Pan, X., Tang, J., Li, J., Guo, Z., Zhang, G., 2010. Levels and distributions of PBDEs and PCBs in sediments of the Bohai Sea, North China. J. Environ. Monit. 12, 1234-1241.

Pan, X., Tang, J., Li, J., Zhong, G., Chen, Y., Zhang, G., 2011. Polybrominated diphenyl ethers (PBDEs) in the riverine and marine sediments of the Laizhou Bay area, North China. J. Environ. Monit. 13, 886-893.

Ricklund, N., Kierkegaard, A., Mclachlan, Michael S., 2010. Levels and potential sources of decabromodiphenyl ethane (DBDPE) and decabromodiphenyl ether
(DecaBDE) in lake and marine sediments in Sweden. Environ. Sci. Technol. 44, 5. Robson, M., Melymuk, L., Bradley, L., Treen, B., Backus, S., 2013. Wet deposition of brominated flame retardants to the Great Lakes basin-status and trends. Environ. Pollut. 182, 299-306.

SOA, 2014a. China Marine Environment Quality Bulletin 2014.

SOA, 2014b. China Marine Statistical Yearbook 2013. China Ocean Press, Beijing.

Syed, J.H., Malik, R.N., Li, J., Wang, Y., Xu, Y., Zhang, G., Jones, K.C., 2013. Levels profile and distribution of dechloran plus (DP) and polybrominated dipheny ethers (PBDEs) in the environment of Pakistan. Chemosphere 93, 1646-1653.

UNEP, 2009. The New POPs Under the Stockholm Convention.

Wang, D.G., Alaee, M., Sverko, E., Li, Y.F., Reiner, E.J., Shen, L., 2011. Analysis and occurrence of emerging chlorinated and brominated flame retardants in surficial sediment of the Dalian coastal area in China. J. Environ. Monit. 13, 3104-3110.

Wang, L., Zhao, Q., Zhao, Y., Zheng, M., Lou, Y., Yang, B., 2015a. New non-PBDE brominated flame retardants in sediment and plant samples from Jiaozhou Bay wetland. Mar. Pollut. Bull. 97, 512-517.

Wang, X., Xi, B., Huo, S., Deng, L., Pan, H., Xia, X., Zhang, J., Ren, Y., Liu, H., 2013. Polybrominated diphenyl ethers occurrence in major inflowing rivers of Lake Chaohu (China): characteristics, potential sources and inputs to lake. Chemosphere 93, 1624-1631.

Wang, X.T., Chen, L., Wang, X.K., Zhang, Y., Zhou, J., Xu, S.Y., Sun, Y.F., Wu, M.H. 2015b. Occurrence, profiles, and ecological risks of polybrominated diphenyl ethers (PBDEs) in river sediments of Shanghai, China. Chemosphere 133, 22-30.

Wang, Z., Ma, X., Lin, Z., Na, G., Yao, Z., 2009. Congener specific distributions of polybrominated diphenyl ethers (PBDEs) in sediment and mussel (Mytilus edulis) of the Bo Sea, China. Chemosphere 74, 896-901.

Wikipedia, 2015. Brominated Flame Retardant.

Yang, Y., Pan, J., Li, Y., Ying, X., 2004. Persistent organic pollutants PCNs and PBDEs in sediments from coastal waters of Qingdao, Shandong Peninsula. Chin. Sci. Bull. 49, 98.

Yang, Z.S., Liu, J.P., 2007. A unique Yellow River-derived distal subaqueous delta in the Yellow Sea. Mar. Geol. 240, 169-176.

Zeng, L.X., Yang, R.Q., Zhang, Q.H., Zhang, H.D., Xiao, K., Zhang, H.Y., Wang, Y.W. Lam, P.K.S., Jiang, G.B., 2014. Current levels and composition profiles of emerging halogenated flame retardants and dehalogenated products in sewage sludge from municipal wastewater treatment plants in China. Environ. Sci. Technol. 48, 12586-12594.

Zhang, Z.W., Sun, Y.X., Sun, K.F., Xu, X.R., Yu, S., Zheng, T.L., Luo, X.J., Tian, Y., Hu, Y.X. Diao, Z.H., Mai, B.X., 2015. Brominated flame retardants in mangrove sediments of the Pearl River Estuary, South China: spatial distribution, temporal trend and mass inventory. Chemosphere 123, 26-32.

Zhao, X., Zheng, B., Qin, Y., Jiao, L., Zhang, L., 2010. Grain size effect on PBDE and PCB concentrations in sediments from the intertidal zone of Bohai Bay, China. Chemosphere 81, 1022-1026.

Zhao, Y., Ma, J., Qiu, X., Lin, Y., Yang, Q., Zhu, T., 2013a. Gridded field observations of polybrominated diphenyl ethers and decabromodiphenyl ethane in the atmosphere of north China. Environ. Sci. Technol. 47, 8123-8129.

Zhao, Y., Ma, J., Qiu, X., Lin, Y., Yang, Q., Zhu, T., 2013b. Gridded field observations of polybrominated diphenyl ethers and decabromodiphenyl ethane in the atmosphere of North China. Environ. Sci. Technol. 47, 8123-8129.

Zhao, Z., Zhong, G., Moller, A., Xie, Z., Sturm, R., Ebinghaus, R., Tang, J., Zhang, G. 2011. Levels and distribution of dechlorane plus in coastal sediments of the Yellow Sea, North China. Chemosphere 83, 984-990.

Zheng, B., Zhao, X., Liu, L., Li, Z., Lei, K., Zhang, L., Qin, Y., Gan, Z., Gao, S., Jiao, L., 2011 Effects of hydrodynamics on the distribution of trace persistent organic pollutants and macrobenthic communities in Bohai Bay. Chemosphere 84 336-341.

Zheng, Q., Nizzetto, L., Li, J., Mulder, M.D., Sanka, O., Lammel, G., Bing, H., Liu, X., Jiang, Y., Luo, C., Zhang, G., 2015. Spatial distribution of old and emerging flame retardants in Chinese forest soils: sources, trends and processes. Environ. Sci. Technol. 49, 2904-2911.

Zhu, B., Lam, J.C., Yang, S., Lam, P.K., 2013. Conventional and emerging halogenated flame retardants (HFRs) in sediment of Yangtze River Delta (YRD) region, East China. Chemosphere 93, 555-560. 